\title{
Numerical Study of the Process of Salt Water Inflow to the Don Mouth from the Taganrog Bay
}

\author{
A. L. Chikin ${ }^{1,}{ }^{凶}$, L. G. Chikina ${ }^{2}$ \\ ${ }^{1}$ Federal Research Center the Southern Scientific Center of Russian Academy of Sciences, \\ Rostov-on-Don, Russian Federation \\ 2 Southern Federal University, Rostov-on-Don, Russian Federation \\ 凶chikin1956@gmail.com
}

\begin{abstract}
Purpose. Numerical study based on the model example is aimed at examining the process of the salt water inflow to the Stary Don sleeve from the Taganrog Bay due to the wind water surge.

Methods and Results. Complex mathematical model of the flow and salt distribution in the open riverbed is described. The section of the River Don, consisting of the Stary Don sleeve and a part of the main channel was considered. Salt is delivered through the host reservoir - the Taganrog Bay. The model is described by the system of Saint-Venant equations and the convection-diffusion equation. The problem is solved by the finite-difference methods. The results of the numerically studied influence of the sea surface level in the Taganrog Bay both on the flow nature in the Don Delta area and the degree of salt penetration upstream of the river are obtained. It was numerically established that the flow rate did not significantly affect salt concentration in the Don main channel.

Conclusions. The computational experiments showed that the decisive factor in the process of the salt water inflow to the Don Delta from the Taganrog Bay consisted in the sea level significant increase resulting from extreme wind surges; and the preceding runoffs enhanced this effect even greater. The represented model gives an idea of the general trend in the process of the Don Delta possible salinization as a result of the surge phenomena.
\end{abstract}

Keywords: channel flow, river delta, Saint-Venant equations, convection-diffusion equation, tidestorm surge oscillations, computational experiment

Acknowledgements: the problem of the study was posed within the framework of the state task to the Southern Scientific Center of Russian Academy of Sciences, project No. AAAA-A18-118122790121-5, the numerical modeling methods were developed within the framework of the RFBR scientific project No. 18-05-80025 "Dangerous phenomena". Calculations were performed at the Center for Collective Use of the Southern Federal University "High Performance Computing".

For citation: Chikin, A.L. and Chikina, L.G., 2021. Numerical Study of the Process of Salt Water Inflow to the Don Mouth from the Taganrog Bay. Physical Oceanography, [e-journal] 28(2), pp. 228237. doi:10.22449/1573-160X-2021-2-228-237

DOI: $10.22449 / 1573-160 X-2021-2-228-237$

(C) A. L. Chikin, L. G. Chikina, 2021

(C) Physical Oceanography, 2021

\section{Introduction}

In the Azov Sea basin such phenomena as the Taganrog Bay salinization, the Don channel shallowing, extreme surges on the seashore and overgrowing of the delta front and migration of the Azov Sea fauna representatives to the Don delta have recently started to be observed [1]. Under the Don runoff impact, the desalinated water mass of the Taganrog Bay is formed.

The Taganrog Bay of the Azov Sea and the Don mouth area are currently characterized by a complex combination of fresh, slightly saline and brackish waters. It was found that in the mouth area, even during surges, a significant increase in salinity (up to $5 \%$ ) is recorded. It indicates a sharply increased role of the Azov-Black Sea compensation current [2, 3]. 
As a result of a decrease in the runoff of the rivers flowing into the Azov Sea, the difference in the level of the Azov and Black Seas decreases. It leads to an increase in the salt supply from the Black Sea through the Kerch Strait and a change in the general balance of salt and fresh waters in the basin. These changes are especially noticeable in the Taganrog Bay, where significant salinization of waters is observed at certain intervals [4]. Under certain hydrometeorological conditions, salty waters penetrate even into the Don mouth, where the fresh water intake is located.

Simulation of the Don waters propagation in the Azov Sea without taking into account external influences was carried out in [5]. It was established that the runoff currents constitute an alongshore cyclonic stream encircling the Azov Sea. It is shown that the frontal zone in the Taganrog Bay, due to the Don runoff, is the most dynamically active area.

Analysis of the features of the hydrochemical regime of the Nizhniy Don water area under conditions of different water content and the Don runoff impact on the Taganrog Bay productivity was carried out in [6].

A serious threat is posed by significant surge phenomena during extreme east winds and run-ups - under western winds. It has been established [7] that the situation is especially dangerous when water is driven off before the surge. With a sharp change from the eastern wind to the western, inundation occurs faster and is stronger in scale than with a constantly acting western wind. A similar pattern was observed on September 23, 2013, when the eastern wind of 3-11 m/s changed to a southwestern one of $15 \mathrm{~m} / \mathrm{s}$ with gusts of $20-22 \mathrm{~m} / \mathrm{s}$.

During the extreme surge in June 2014, the sea level rose to $1.7 \mathrm{~m}$, and the salinity at the Don mouth reached 5 \% [8]. In September 2014, as a result of a surge, waters with increased (5-9\%) salinity were pressed against the avandelta. Water with salinity up to $6 \%$, typical for the Dolzhanskaya - Mariupol spit area, penetrated along the Don at least to the city of Azov, where it was pumped into the city water supply system.

Causes of anomalous scale water surges and salinization of the Azov Sea in 2015-2016 are studied in [2]. New schemes of stratification and advection of saline sea waters at the mouth of the Don under various meteorological conditions, flow rates and water levels are also described in this paper.

The Don mouth area consists of the estuary section (from Razdorskaya stanitsa to the delta top in the Rostov-on-Don region), its delta and the Taganrog Bay is characterized by the manifestation of surging level fluctuations, the inflow of transformed sea waters into the Don, which was especially pronounced during the low water period 2007-2017 [9, 10].

The work [11] is devoted to the calculation of hydrological parameters of channel flows at estuarine sections of rivers, where an approach to estimation of the Don delta discharge and levels based on the unsteady water flow concept is proposed, but the issue of their changes with fluctuations in runoff volumes is not practically considered. In [12], an example of a joint consideration of the river runoff variability and surge fluctuations in the level of a trailing water body.

A model containing both a hydrodynamic and transport component is given in [13], which describes the penetration of salinity into tidal river mouths. This work on alluvial estuaries considers the shape of the estuary, its hydrodynamics, mixing 
and salt penetration. The water salinity at the river mouth is the result of a balance between two opposing streams: the seawater flow generated by the tide and infiltrating the estuary, and the fresh water flow from the channel.

In [14], one-dimensional time-averaged solutions associated with tidal salinity penetration into estuaries with variable width and depth are studied.

The aim of the present paper is a numerical study on a model example of the process of the salt water inflow of the Taganrog Bay into the Stary Don reach due to a wind surge. The influencing factors are a change in the water level and salt concentration in the bay, as well as a change in the flow rate of water entering the channel from the Tsimlyansk reservoir.

\section{Main Equations}

Process of saline water penetration from the Taganrog Bay into the Don estuary is considered on the example of the main channel and the Stary Don reach stretching from the Razdorskaya stanitsa to the place where it flows into the Taganrog Bay.

The mathematical model consists of two components - hydrodynamic and transport one. The hydrodynamic component is described by the equation of motion $[15,16]$

$$
\left\{\begin{array}{l}
\frac{\partial Q}{\partial t}+g W\left(\frac{\partial z}{\partial s}+\frac{Q|Q|}{K^{2}}\right)=0, \\
\frac{\partial W}{\partial t}+\frac{\partial Q}{\partial s}=q,
\end{array}\right.
$$

where $s$ is a coordinate; $t$ is time; $Q$ is water flow; $z$ is water level; $W$ is the crosssectional area; $q$ is the distributed lateral inflow; $K$ is the flow module; $g$ is the free fall acceleration.

This system is closed by the boundary and initial conditions:

$$
\begin{array}{ll}
Q(0, t)=Q_{1}(t), & z(L, t)=z_{1}(t), \\
Q(s, 0)=Q_{0}(s), & z(x, 0)=z_{0}(s) .
\end{array}
$$

In the case when the free cross-section of the channel has a parabolic profile, system (1) can be written in the following form

$$
\left\{\begin{array}{l}
\frac{\partial Q}{\partial t}+g W\left(\frac{\partial z}{\partial s}+\frac{Q|Q|}{K^{2}}\right)=0, \\
b \frac{\partial z}{\partial t}+\frac{\partial Q}{\partial s}=q,
\end{array}\right.
$$

where $b$ is the current channel width. A detailed description of the numerical implementation of the hydrodynamic component (2) is given in [17].

The transport component of a conservative substance in the absence of internal sources is described by the convection-diffusion equation in a non-divergent form: 


$$
\frac{\partial C}{\partial t}+u \frac{\partial C}{\partial s}-\mu \frac{\partial^{2} C}{\partial s^{2}}=0
$$

where $C$ is concentration; $u$ is a speed of water movement in the channel; $\mu$ is the viscosity coefficient. It is assumed that the viscosity coefficient does not depend on the point in space ( $\mu=$ const).

At the upper boundary of the channel (entrance), the concentration value is set, for example, it can be assumed that there is no salt $(C=0)$. At the lower boundary (mouth), the condition changes depending on the sign of the current velocity. When water flows from the bay to the mouth $(u<0)$, as it happens during strong surges, a condition is set $\frac{\partial C}{\partial s}=\frac{u}{\mu}\left(C-C_{\text {zal }}\right)$ - the flow of salt from the bay to the mouth. Under normal conditions, or when the water flows from the mouth to the bay $(u>0)$, a condition $\frac{\partial C}{\partial s}+C \frac{u}{\mu}=0$ is set that corresponds to the removal of salt from the mouth.

The finite-difference approximation of the equation (3) on a uniform grid has the form

$$
\frac{\delta C}{\delta t}+u \frac{\delta C}{\delta s}-\mu \frac{\delta^{2} C}{\delta s^{2}}=0,
$$

and the general form of the difference equation is as follows:

$$
a_{1} C_{j-1}+a_{2} C_{j}+a_{3} C_{j+1}=f_{j}, j=1,2, \ldots, M .
$$

In equation (4), the differences are represented in the following way:

$$
\frac{\delta C}{\delta t}=\frac{C_{j}^{n+1}-C_{j}^{n}}{\Delta t}, \quad \frac{\delta^{2} C}{\delta s^{2}}=\frac{C_{j+1}^{n+1}-2 C_{j}^{n+1}+C_{j-1}^{n+1}}{\Delta s^{2}} .
$$

The coefficients $a_{1}, a_{2}, a_{3}$, and the right part of $f_{j}$ in (5) without taking in account the convective component have the form

$$
a_{1}=-\frac{\mu}{\Delta s^{2}} \Delta t, a_{2}=1+\frac{2 \mu}{\Delta s^{2}} \Delta t, a_{3}=-\frac{\mu}{\Delta s^{2}} \Delta t, f_{j}=c_{j}^{n} .
$$

To the coefficients $a_{1}, a_{2}, a_{3}$ the terms obtained from the approximation of the convective component using the second upstream scheme [18] are added: $u \frac{\delta C}{\delta s}=\frac{u_{R} C_{R}-u_{L} C_{L}}{\Delta s}$,

where $u_{R}=\frac{u_{j+1}^{n+1}+u_{j}^{n+1}}{2} ; u_{L}=\frac{u_{j-1}^{n+1}+u_{j}^{n+1}}{2}$;

$$
C_{R}=\left\{\begin{array}{ll}
C_{j}^{n+1}, & u_{R}>0, \\
C_{j+1}^{n+1}, & u_{R}<0,
\end{array} C_{L}= \begin{cases}C_{j-1}^{n+1}, & u_{L}>0 \\
C_{j}^{n+1}, & u_{L}<0\end{cases}\right.
$$




\section{Calculations on a model problem}

The computational grid consisted of 154 nodes with a step of $1000 \mathrm{~m}$, the channel morphometric data were taken from [19]. As the initial distribution of the flow parameters, the parameters obtained at a steady flow for a median flow rate of $535 \mathrm{~m}^{3} / \mathrm{s}$ [17] and a water level in the Taganrog Bay of $0 \mathrm{~m}$ (according to the Baltic system) were taken. The calculations were carried out for a time period of 48 hours. Several scenarios, typical for the estuary of the Don were considered. According to Scenario I, the water level at the right boundary at first sharply and then gradually increased (the case of a surge), then remained at rest for some time, and then decreased. It was assumed that the salt concentration is constant and equal to $2 \%$, the incoming water flow is $535 \mathrm{~m}^{3} / \mathrm{s}$. The dependence of the change in the water level at the estuary point $z(\mathrm{~cm})$ on time $t(\mathrm{~h})$ is represented by the following formula:

$$
z(t)= \begin{cases}0,15 t, & t \leq 12, \\ 1,80+0,10(t-12) & , 12<t \leq 18, \\ 2,40, & 18<t \leq 20, \\ 2,40-0,15(t-20), & 20<t \leq 26, \\ 1,50-0,05(t-26), & 26<t \leq 48 .\end{cases}
$$

According to Scenario II, the change in salt concentration at the estuary point was added to the water level change. At a constant flow rate of $535 \mathrm{~m}^{3} / \mathrm{s}$, this scenario assumed a change in the water level at the estuary point according to formula (6) and a change in salt concentration in the estuary area according to the formula

$$
C(t)= \begin{cases}0,2 t, & t \leq 12, \\ 2,4+0,5(t-12), & 12<t \leq 20, \\ 6,4-0,9(t-20), & 20<t \leq 26, \\ 1,0-0,08(t-26), & 26<t \leq 48 .\end{cases}
$$

Such values of salt concentration are possible when seawater is supplied due to extreme wind surges [20].

Scenario III assumes a change not only in the water level in the receiving reservoir (6) and salinity at the estuary point (7), but also in the flow rate of the water entering the channel. At first, the water flow rate increased from a reduced value of $250 \mathrm{~m}^{3} / \mathrm{s}$ to an increased value of $610 \mathrm{~m}^{3} / \mathrm{s}$, then it decreased to $412 \mathrm{~m}^{3} / \mathrm{s}$, corresponding to the normal value of the water flow rate [1], and remained unchanged until the end of the experiment. The dependence of the change in the flow rate of the incoming water $\left(\mathrm{m}^{3} / \mathrm{s}\right)$ on the time $t$ (h) is represented by the following formula: 


$$
Q(t)= \begin{cases}250+10 t, & t \leq 12, \\ 370+30(t-12), & 12<t \leq 20, \\ 610-33(t-20), & 20<t \leq 26, \\ 412, & 26<t \leq 48\end{cases}
$$

Since the salinity propagation is mainly associated with the convection process, special attention was paid to the numerical study of the influence of the flow rate of the incoming water and the level in the receiving reservoir on the flow rate in the channel. A numerical study has shown that the current velocity at points close to the river mouth is not influenced as strongly by the change in the water level in the receiving reservoir. Moreover, the influence of the water level weakens as it moves upstream, corresponding to the conclusions given in [10]. Fig. 1 shows the values of the current velocity at points corresponding to observation points located along the main channel: Azov (16 km from the Don mouth), Rostov-on-Don (44 km), Aksai (64 km), Bagaevskaya (112 km) and Razdorskaya $(152 \mathrm{~km})$. It can be seen that the change in the water level in the Taganrog Bay, which occurs according to dependence (6), has the greatest effect on the current velocity in the Azov region and upstream has little effect on it in the area of the Razdorskaya stanitsa. The formation of a reverse current (the graphs correspond to negative values of the velocity) under this scenario is possible up to Aksai.

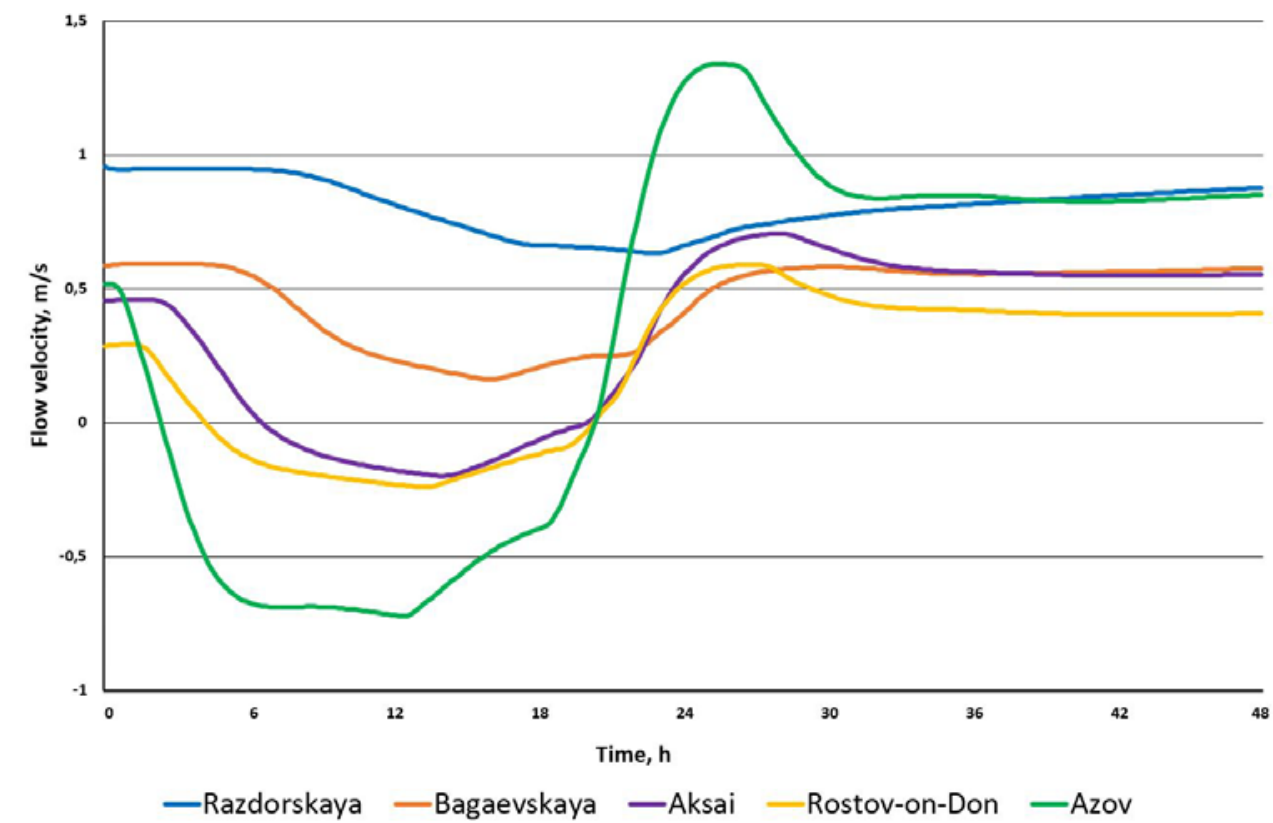

F i g. 1. Changes in the current velocity in different points of the Don channel when the sea level in the Taganrog Bay alters

Fig. 2, in addition to the graph of the water level in the receiving reservoir, graphs of the current velocity are shown at a point located at a distance of $16 \mathrm{~km}$ PHYSICAL OCEANOGRAPHY VOL. 28 ISS. 2 (2021) 
from the mouth, which corresponds to the location of the Azov port. Scenario I assumes a change in the water level according to dependence (6) at a constant flow rate, scenario III - a change in the water level and flow rate according to dependence (8). It can be seen that the current velocity curves for these two scenarios behave almost the same, which indicates an insignificant effect of the discharge of water entering the channel on the current velocity at the river mouth. The difference in the current velocities in the Azov region, calculated according to scenarios I and III, is $14 \%$. The error was calculated by the formula

$$
\delta=\frac{\sqrt{\sum_{j}\left(V_{j}^{\mathrm{I}}-V_{j}^{\mathrm{III}}\right)^{2}}}{\sqrt{\sum_{j}\left(V_{j}^{\mathrm{I}}\right)^{2}}} 100 \%,
$$

where $V_{j}^{\mathrm{I}}$ are the velocities according to Scenario I; $V_{j}^{\mathrm{III}}$ are the velocities according to Scenario III.

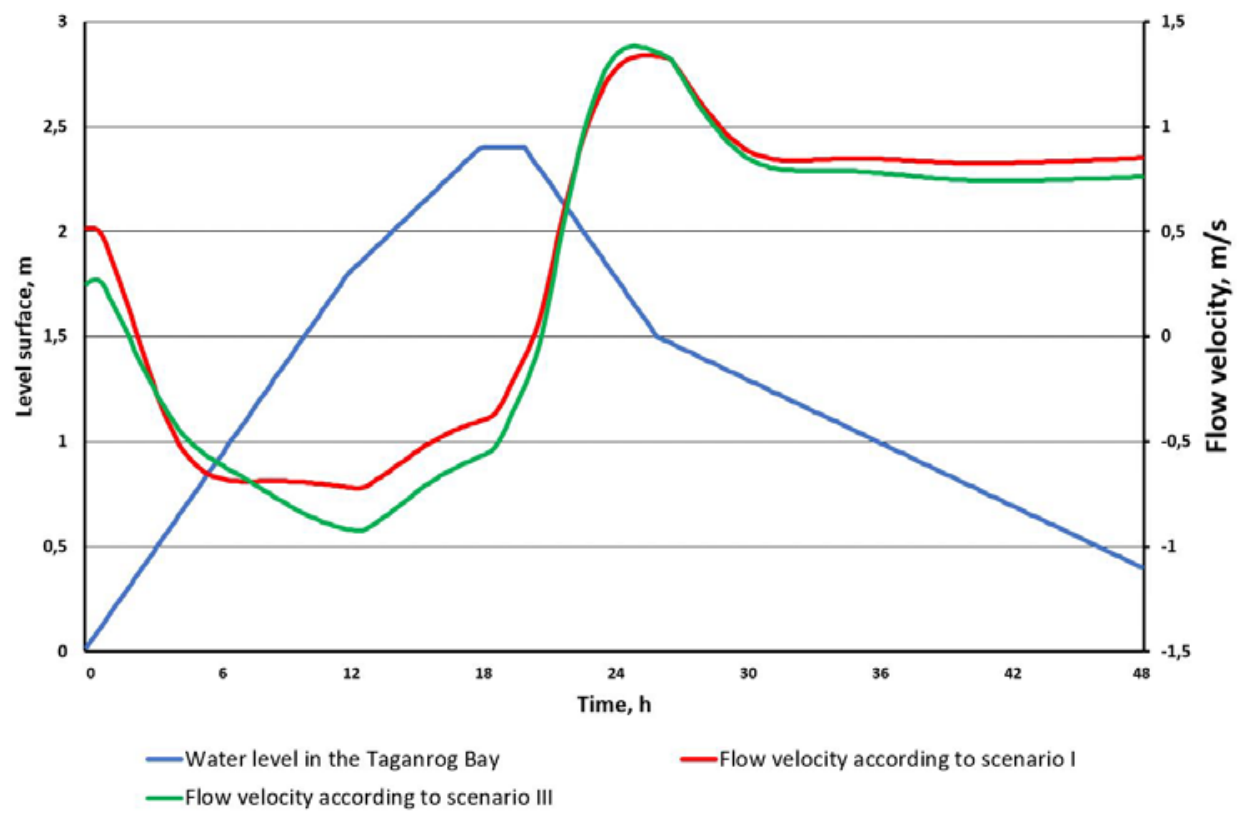

F i g. 2. Changes in the current velocity in the Taganrog Bay depending on the sea level (according to the Baltic system) in the host reservoir

Hence, it follows that the change in the Stary Don reach salinity depends to a greater extent on the change in the water level in the Taganrog Bay, and not on the flow rate of the incoming water. In addition, it was numerically established that with a slow increase in the water level in the receiving reservoir, a reverse flow does not appear. Salt water can enter the mouth of a river only when the water level in the receiving water body rises sharply.

Coming back to Fig. 2, the current velocity in the Azov region, depending on the water level change in the Taganrog Bay will be considered. It can be seen that 
with a sufficiently sharp water level elevation, the current velocity begins to drop to zero, and then takes negative values corresponding to the reverse current of the river. Then, when the water elevation stops, the reverse current is inhibited and with a subsequent decrease in the water level, the velocity starts to increase to positive values, which corresponds to the occurrence of a direct current, which stabilizes as the level returns to the initial value.

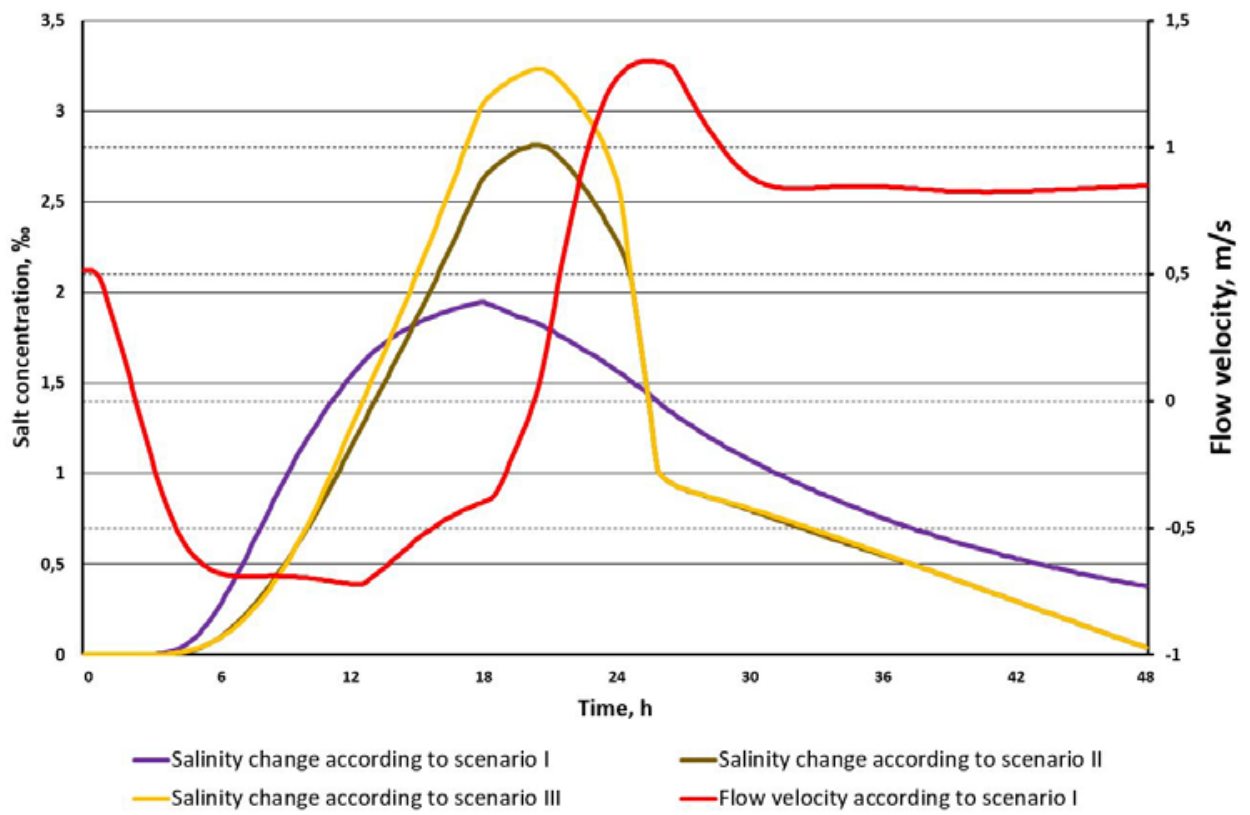

F i g. 3. Changes of salinity in the Azov region by three scenarios depending on the current velocity

The change in current velocity and salinity is shown in Fig. 3. As previously established, since the current velocities differ insignificantly under scenarios I, II and III, the figure shows the current velocity only for scenario I. The change in salt concentration depends on both the current velocity and the direction of the flow. At the initial moment, the concentration was equal to zero, which corresponds to fresh water, and then began to increase as soon as the current velocity became negative. The salt concentration increased until the reverse flow stopped $(\mathrm{V}=0)$. Then the salt concentration began to decrease with the appearance of a direct current in the channel. The significant difference in concentration values for scenarios II and III in the first 12 hours of the estimated time is explained by the fact that the initial water discharge under Scenario III was significantly lower than the average considered. For this reason, the current velocity in the channel was initially lower, which led to a faster inflow of salt water into the Don reach. In the following hours (from the $12^{\text {th }}$ to the $26^{\text {th }}$ ), when a sharp change in the water level was observed, the concentration difference was $9.5 \%$. From the $26^{\text {th }}$ hour until the end of the experiment, the higher concentration in Scenario III is explained by a lower flow rate of the incoming water, which leads to a lower current velocity and, therefore, to a slower removal of salt from the channel. 


\section{Conclusion}

The computational experiments carried out on the model problem showed that the salt water inflow from the Taganrog Bay into the Don delta is decisively influenced by a sharp water level increase, which can lead to the penetration of salt water to Rostov and Aksai. Extreme wind surges lead to significant water level elevations, and the preceding surges intensify this effect even more. In addition, surges can lead to the saltier water inflow from the south of the Azov Sea, which in turn significantly increases the salinity in the mouth area of the Taganrog Bay. The study of the surge phenomena at the Don mouth showed the presence of complex hydrodynamic processes in them. The proposed model gives an idea of the general trend in the development of the possible salinization process of the Don delta during surges.

\section{REFERENCES}

1. Matishov, G.G., Grigorenko, K.S. and Moskovets, A.Yu., 2017. The Salinization Mechanisms in the Taganrog Bay under the Conditions of the Don River Extremely Low Runoff. Nauka Yuga Rossii, 13(1), pp. 35-43. doi:10.23885/2500-0640-2017-13-1-35-43 (in Russian).

2. Matishov, G.G. and Grigorenko, K.S., 2017. Causes of Salinization of the Gulf of Taganrog. Doklady Earth Sciences, 477(1), pp. 1311-1315. https://doi.org/10.1134/S1028334X17110034

3. Matishov, G.G., Kovaleva, G.V. and Jasakova, O.N., 2016. Anomalous High Salinity in the Taganrog Bay Estuary and the Don Delta. Nauka Juga Rossii, 12(1), pp. $43-50$ (in Russian).

4. Fomin, V.V., Polozok, A.A. and Fomina, I.N., 2015. Simulation of the Azov Sea Water Circulation Subject to the River Discharge. Physical Oceanography, (1), pp. 15-26. doi:10.22449/1573-160X-2015-1-15-26

5. Mizyuk, A.I., Korotaev, G.K., Grigoriev, A.V., Puzina, O.S. and Lishaev, P.N., 2019. LongTerm Variability of Thermohaline Characteristics of the Azov Sea Based on the Numerical Eddy-Resolving Model. Physical Oceanography, 26(5), pp. 438-450. doi:10.22449/1573160X-2019-5-438-450

6. Kosenko, Yu.V., Baskakova, T.E. and Kartamysheva, T.B., 2018. Role of the Don River Flow in Productivity Formation of the Taganrog Bay. Aquatic Bioresources \& Environment, 1(34), pp. 32-39. doi:10.47921/2619-1024_2018_1_3-4_32 (in Russian).

7. Matishov, G.G., Chikin, A.L., Berdnikov, S.V. and Sheverdyaev, I.V., 2014. The Extreme Flood in the Don River Delta, March 23-24, 2013, and Determining Factors. Doklady Earth Sciences, 455(1), pp. 360-363. https://doi.org/10.1134/S1028334X14030295

8. Matishov, G.G., 2015. Extreme Saline Water Advection into the Don River Delta and Ice Advections into Kerch Strait. Doklady Earth Sciences, 465(1), pp. 1154-1158. https://doi.org/10.1134/S1028334X15110057

9. Ostroumova, L.P., 2017. Investigation of Surges in Marine Estuaries (A Case Study for the Don River Mouth). Russian Meteorology and Hydrology, 42(12), pp. 792-802. https://doi.org/10.3103/S106837391712007X

10. Simov, V.G., 1989. [Hydrology of the Mouths of the Rivers of the Sea of Azov]. Moscow: Gidrometeoizdat, 328 p. (in Russian).

11. Mishin, D.V. and Polonskiy, V.F., 2013. Research of Non-Stationary Water Streams in Nontidal Mouth of Don River. In: SOI, 2013. SOI Proceedings. Moscow: SOI. Issue 214, pp. 166-179 (in Russian).

12. Polonskii, V.F. and Ostroumova, L.P., 2002. Probabilistic Estimates of Water Level in the Ural River Mouth Reach at Interaction between the River Runoff and Positive Setups. Water Resources, 29(5), pp. 497-505. https://doi.org/10.1023/A:1020365512557

13. Savenije, H.H.G., 2012. Salinity and Tides in Alluvial Estuaries. Second Completely Revised Edition. Available at: http://www.salinityandtides.com [Accessed: 08 January 2015]. 
14. Prandle, D., 1981. Salinity Intrusion in Estuaries. Journal of Physical Oceanography, 11(10), pp. 1311-1324. https://doi.org/10.1175/1520-0485(1981)011<1311:SIIE>2.0.CO;2

15. Grushevskiy, M.S., 1969. [Release and Flood Waves in the River]. Leningrad: Gidrometeoizdat, 338 p. (in Russian).

16. Koren, V.I., 1991. Mathematical Models for the Forecasts of Runoff. Leningrad: Gidrometeoizdat, 200 p. (in Russian).

17. Chikin, A.L., Kleshchenkov, A.V., Chikina, L.G. and Korshun, A.M., 2017. Wind-Driven Water Level Variation of the Mouth Area of the Don: Numerical Modelling and Change Scenarios. Nauka Juga Rossii, 13(3), pp. 39-49 (in Russian).

18. Roache, P.J., 1972. Computational Fluid Dynamics. Albuquerque: Hermosa Publishers, $434 \mathrm{p}$.

19. GBU “Volgo-Balt”, 2006. [Atlas of the Unified Deep-Water System of the European Part of Russia. Volume 8. Part 2. Volga-Don Waterway. From Volgodonsk to the Mouth of the Don]. Saint-Petersburg: Volgo-Balt, 40 p. (in Russian).

20. Matishov, G.G. and Grigorenko, K.S., 2018. Water Scarcity and the Role of Groundwater in Salinization of the Don Avandelta. Doklady Earth Sciences, 483(3), pp. 1528-1533. https://doi.org/10.1134/S1028334X18120073

About the authors:

Aleksey L. Chikin, Chief Research Associate, Federal Research Centre the Southern Scientific Centre of Russian Academy of Sciences (41 Chekov St., Rostov-on-Don, 344006, Russian Federation), Dr. Sci. (Phys.-Math), SPIN-code: 3845-9760, ORCID ID: 0000-0002-4065-010X, Scopus Author ID: 8240627300, chikin1956@gmail.com

Lyubov G. Chikina, Professor, Southern Federal University (105 Bolshaya Sadovaya St., Rostov-on-Don, 344006, Russian Federation), Dr. Sci. (Phys.-Math), SPIN-code: 4295-3950,ORCID ID: 0000-0002-2935-5839, Scopus Author ID: 6506085787, lchikina@sfedu.ru

Contribution of the co-authors:

Aleksey L. Chikin - the research initiator; development of a mathematical model; preparation of the initial version of the text; revision of the text; constructing tables, graphs and charts

Lyubov G. Chikina - selection and justification of numerical methods for solving equations; correction of the mathematical model and calculations; computer implementation of the algorithms

All the authors have read and approved the final manuscript.

The authors declare that they have no conflict of interest. 